\title{
Esophagus and Esophagogastric Junction Cancer Clinical TNM Finding v7
}

National Cancer Institute

\section{Source}

National Cancer Institute. Esophagus and Esophagogastric Junction Cancer Clinical TNM

Finding v7. NCI Thesaurus. Code C89745.

A clinical finding about one or more characteristics of esophagus and esophagogastric junction cancer, following the rules of the TNM AJCC V7 classification system. Clinical classification is based on evidence before primary treatment. It involves esophagoscopy with biopsy, endoscopic esophageal ultrasound (EUS), EUS-directed fine-needle aspiration (EUS-FNA), fused computed tomography (CT), PET/CT for assessment of T, N, M, and G classifications, and histopathologic type. Clinical reclassification during or following chemotherapy and/or radiotherapy is designated by the prefix yc. (from AJCC 7th Ed.) 